\title{
Review Article \\ Propionibacterium acnes: An Underestimated Pathogen in Implant-Associated Infections
}

\author{
María Eugenia Portillo, ${ }^{1}$ Stéphane Corvec, ${ }^{2,3}$ Olivier Borens, ${ }^{4}$ and Andrej Trampuz \\ ${ }^{1}$ Microbiology Laboratory, Laboratori de Referencia de Catalunya, Barcelona, Spain \\ ${ }^{2}$ Service de Bactériologie-Hygiène, CHU de Nantes, Institut de Biologie, Nantes Cedex, France \\ ${ }^{3}$ Université de Nantes, EA3826, Thérapeutiques Cliniques et Expérimentales des Infections, 1 rue G. Veil, 44000 Nantes, France \\ ${ }^{4}$ Orthopedic Septic Surgical Unit, Department of Surgery and Anesthesiology, Lausanne University Hospital, Lausanne, Switzerland \\ ${ }^{5}$ Center for Musculoskeletal Surgery, Charité-University Medicine Berlin, Free University and Humboldt University, Charitéplatz 1, \\ 10117 Berlin, Germany
}

Correspondence should be addressed to Andrej Trampuz; andrej.trampuz@gmail.com

Received 11 January 2013; Revised 20 August 2013; Accepted 4 October 2013

Academic Editor: Andrew McDowell

Copyright (c) 2013 María Eugenia Portillo et al. This is an open access article distributed under the Creative Commons Attribution License, which permits unrestricted use, distribution, and reproduction in any medium, provided the original work is properly cited.

\begin{abstract}
The role of Propionibacterium acnes in acne and in a wide range of inflammatory diseases is well established. However, P. acnes is also responsible for infections involving implants. Prolonged aerobic and anaerobic agar cultures for 14 days and broth cultures increase the detection rate. In this paper, we review the pathogenic role of $P$. acnes in implant-associated infections such as prosthetic joints, cardiac devices, breast implants, intraocular lenses, neurosurgical devices, and spine implants. The management of severe infections caused by P. acnes involves a combination of antimicrobial and surgical treatment (often removal of the device). Intravenous penicillin $\mathrm{G}$ and ceftriaxone are the first choice for serious infections, with vancomycin and daptomycin as alternatives, and amoxicillin, rifampicin, clindamycin, tetracycline, and levofloxacin for oral treatment. Sonication of explanted prosthetic material improves the diagnosis of implant-associated infections. Molecular methods may further increase the sensitivity of $P$. acnes detection. Coating of implants with antimicrobial substances could avoid or limit colonization of the surface and thereby reduce the risk of biofilm formation during severe infections. Our understanding of the role of $P$. acnes in human diseases will likely continue to increase as new associations and pathogenic mechanisms are discovered.
\end{abstract}

\section{Introduction}

Propionibacterium acnes is part of the normal human microbiota $[1,2]$. This bacterium is usually responsible for late chronic infections but, exceptionally, could produce acute infections, mainly related to any device. The $P$. acnes genome encodes diverse virulent factors which confer a pathogenic potential to this bacterium [3].

The role of $P$. acnes in the pathogenesis of acne is known for decades. Numerous reports reveal that $P$. acnes has been also associated with chronic prostatitis leading to prostate cancer [4], chronic recurrent multifocal osteomyelitis (CRMO) and synovitis-pustulosis-hyperostosis and osteitis (SAPHO) syndrome [5], sarcoidosis [6, 7], and sciatica [8]. More recently, this microorganism has been recognized as the cause of various types of implant-associated infections, including breast implants $[9,10]$, neurosurgical shunts [11], cardiovascular devices [12], ocular implants [13], internal fracture fixation devices, spinal hardware [14], and prosthetic joints [15] (Figure 1).

\section{Microbiology}

P. acnes is an anaerobic-aerotolerant diphtheroid-like Grampositive bacillus that resides in pilosebaceous follicles of the skin (Figure 2) [1], and is also found in the conjunctiva [2], oral cavity [2], intestinal tract [16], and external ear canal [1]. The $P$. acnes genome encodes all key components of oxidative phosphorylation (NADH dehydrogenase/complex I, 


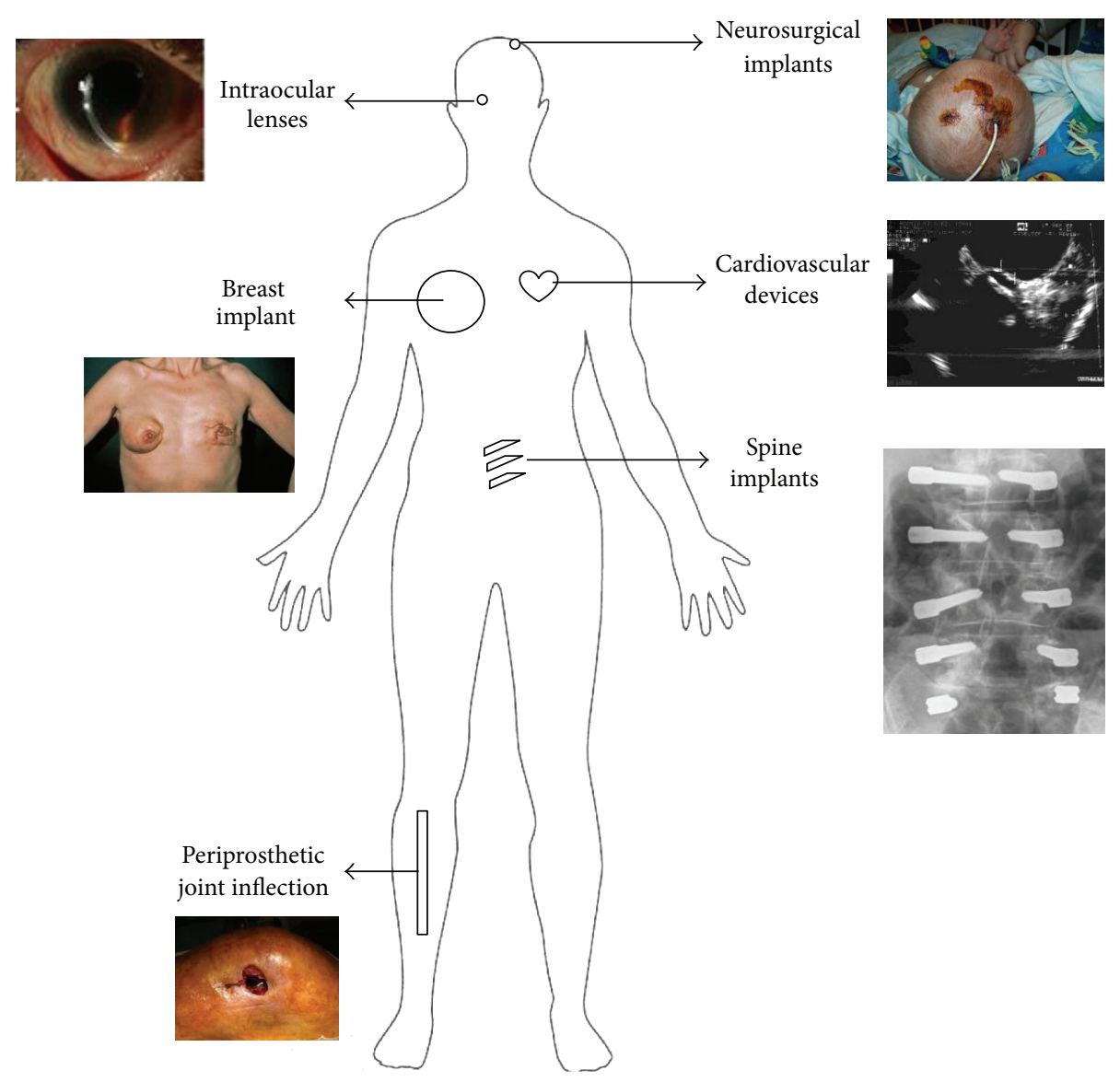

FIgURE 1: Diversity of implant-associated infections caused by P. acnes.

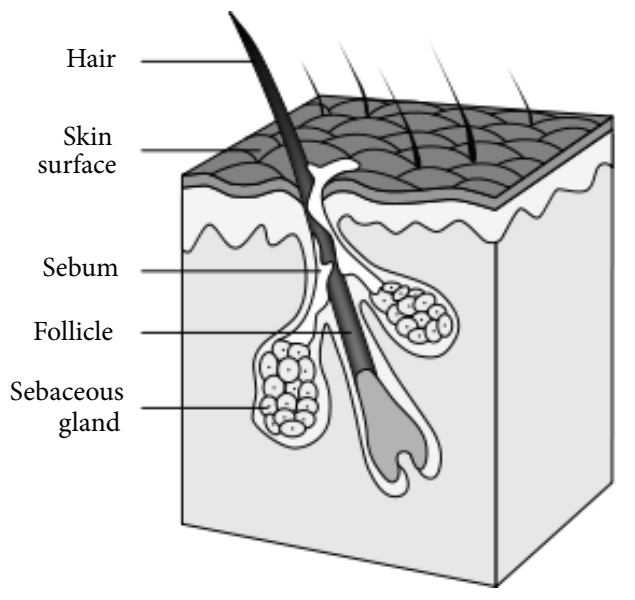

FIGURE 2: Scheme of a normal pilosebaceus unit of human skin. The hair, sebum, and keratinocytes that fill the narrow follicle may produce a plug. The mixture of oil and cells desquamate allows $P$. acnes to grow in the plugged follicles, producing chemicals and enzymes that attract host immune cells causing inflammation. Source: National Institutes of Health (NIH), Department of Health and Human Services.

cytochrome c reductase, cytochrome c oxidase, and FOF1type ATP synthase). In addition, it also possesses the genes for the cytochrome d oxidase, which ensures growth in different conditions $[3,17,18]$. Therefore, P. acnes can tolerate exposure to oxygen for several hours and is capable in vitro to survive under anaerobic conditions for up to 8 months [19]. The latter observation suggests that $P$. acnes can also survive for a prolonged period in human tissues with low oxidation potential $[18,19]$.

Despite its oxygen-tolerant characteristics, $P$. acnes is not reliably detected by aerobic culture due its slow growth [20]. The optimal temperature for growth is $37^{\circ} \mathrm{C}$. To increase the detection, prolonged aerobic and anaerobic agar cultures to 14 days and inoculation into thioglycollate broth should be routinely performed [20-22]. In particular, the low redox potential of enriched thioglycollate broth supports growth of $P$. acnes. Importantly, thioglycollate broth should be routinely subcultured on agar plates despite the absence of visible turbidity of the broth medium [23]. However, a positive culture with $P$. acnes should be interpreted with caution. For example, in case of recovery in broth cultures only or from only one of several tissue samples, additional criteria of infection (such as clinical signs, positive histopathology, or molecular tests) are required [23, 24]. In addition, $P$. acnes should be considered as pathogen in chronic or persistent low-grade implantassociated infections without positive cultures, in which this pathogen is probably underrecognized and underestimated $[25,26]$. 
According to serological agglutination tests and cell wall carbohydrate analysis, $P$. acnes can be classified into two different phylotypes (type I and II) [27, 28]. By sequence analysis of two genes, a nonribosomal housekeeping gene $(\operatorname{rec} A)$ and a gene encoding a putative hemolysin/cytotoxin (tly gene), further discrimination into phylogenetically distinct clusters (type IA, IB, IC, II, and III) is possible [29]. Recently, MALDI-TOF Mass Spectrometry seems to be a useful tool for rapid identification and typing of $P$. acnes [30]. Several genes in the $P$. acnes genome encode different virulent factors such as hemolysins, CAMP factors, lipases, esterases, surface-associated proteins, or cellular factor with antigenic potential $[3,31]$. P. acnes also encodes genes with poly $(\mathrm{C}) /(\mathrm{T})$ stretches. Such variations seem to be involved in phase variation, an adaptation strategy to evade immune responses and degradation [3]. However, from infected prosthesis type IB strains were more frequently isolated than type IA.

Several researchers investigated the association between the pathogenicity of different $P$. acnes phylotypes and their clinical significance $[3,32,33]$. No clear association between phylotypes and infection/colonization has been found. Nevertheless, some phylotypes have been described more frequently in specific infections than others. For instance, in a recent study on shoulder implant infections, $P$. acnes was isolated only in male patients, suggesting that host factors could predispose for infection with this microorganism [34]. Moreover, $P$. acnes type I was predominant in all types of orthopedic implants, except in prosthetic hip joints, in which type I and type II showed equal frequency.

Genomic variation among individual types seems to be low, but there are key differences in genomic islandlike regions encoding a variety of virulence-associated traits [32]. Biofilm formation may be one virulence determinant facilitating implant-associated infections [3]. The genome sequence has revealed three clusters of genes that encode enzymes involved in extracellular polysaccharide biosynthesis and adhesion proteins required for biofilm production [3].

\section{Implant-Associated Infections}

3.1. Periprosthetic Joint Infection. The pathogenesis of periprosthetic joint infection (PJI) is related to microorganisms growing in biofilms, rendering these infections difficult to diagnose and to eradicate [35-37]. PJI can be caused by direct contamination of the surgical wound and the implant during surgery (i.e., perioperative infection), by spreading from a remote infectious focus (i.e., hematogenous infection) or by extension from a neighbored focus or penetrating injury (i.e., contiguous infection) [37]. Staphylococci are the most commonly isolated organisms $(\approx 50 \%)$, followed by streptococci $(\approx 10 \%)$, enterococci $(\approx 10 \%)$, and Gramnegative bacilli $(\approx 10 \%)[37,38]$. The frequency of $P$. acnes is reported in approximately $10 \%$ of PJI, but its frequency is most likely underestimated due to short incubation times in many routine laboratories and its growth being considered as contamination [23]. P. acnes is most frequently associated with shoulder PJI and spine implant-associated infections due to a high concentration of sebaceous follicles at these sites $[15,39]$.

Low-grade infections are typically manifested 3 to 24 months after implantation, or occasionally up to 36 months or longer. As $P$. acnes belongs to the normal skin microbiota, the significance of its growth may be difficult to determine [23]. In low-grade infection, the values of systemic inflammatory biomarkers, such as C-reactive protein (CRP), are often normal [40-42]. Similarly, periprosthetic tissue histopathology may show no acute or only chronic inflammation, reflecting the low virulence and low bacterial burden of $P$. acnes $[40,43]$. A combination of various preoperative and intraoperative tests is needed for accurate diagnosis of low-grade infection of prosthetic joints $[23,44]$. When PJI is diagnosed, a two-stage exchange is usually performed since the prosthesis is typically loosened and retention is not possible anymore. A short interval between prosthesis explantation and reimplantation (i.e., 2-3 weeks) is increasingly used, if $P$. acnes is susceptible to rifampin, the key antibiotic against biofilms [45].

Current diagnostic methods for PJI such as periprosthetic tissue cultures have limited sensitivity, with $10-20 \%$ falsenegative cultures [46]. Recently, molecular techniques have been developed to increase the sensitivity of PJI detection, but $P$. acnes specific primers are not included in such assays $[46,47]$.

Several investigators suggested that some cases of prosthesis failure considered as aseptic may actually be of infectious etiology [48-50]. However, the survival time for joint prosthesis was not shorter when $P$. acnes was cultured in aseptic loosening cases (about 20\% of cases), suggesting that this microorganism may have another, yet unknown, role in such cases [51].

3.2. Cardiac Device Infection. P. acnes infective endocarditis remains rare, although its prevalence is probably underestimated due to diagnostic difficulties [25]. Infection mostly involves prosthetic heart valves [25], annuloplasty rings [52], and pacemaker/ICD leads [53]. Bacteremia or skin wounds are the most frequent port of entry of microorganisms [12]. $P$. acnes infective endocarditis often develops on valve prostheses and embolisms are common. To the best of our knowledge, less than 50 cases of infective endocarditis have been described on prosthetic heart valves, usually the aortic valve prosthesis [25]. Due to subtle symptoms and slow growth of the microorganism, the diagnosis is often late, when valvular and peri-valvular destruction is significant [54]. Antibiotic therapy and surgical intervention with change of the valve are typically needed, and the mortality is high (15-27\%) [12, 55]. The diagnosis of $P$. acnes infective endocarditis using Duke criteria is challenging [56], since echocardiography can be normal and the dysfunction progresses slowly over weeks and months leading to cardiac insufficiency [25, 57, 58]. Fever appears only in approximately $25 \%$ of these patients, and the incidence of neurologic symptoms is higher than that in general complication of infective endocarditis $[25,55]$.

3.3. Breast Implant Infection. Breast implants are increasingly used for aesthetic reasons or in patients after mastectomy 
$[59,60]$. Infection occurs in $1.1 \%$ to $2.5 \%$ after aesthetic breast augmentation and up to $35 \%$ after breast implant reconstruction following mastectomy [61]. These infections are typically caused by bacterial skin flora, such as Staphylococcus aureus and coagulase-negative staphylococci [62]. Acute infections associated with breast implants usually occur during the first month after implantation and are frequently associated with fever, acute pain, and marked breast erythema. In some cases, $P$. acnes could be recovered alone or in combination with staphylococci. Late infections are rare and often associated with bacteremia or an invasive procedure at a location other than the breasts. Risk factors for breast implant infection are breast reconstruction after mastectomy and radiotherapy [62]. Surgical removal of the implant is mandatory in most cases by two-step procedure [63].

Developments in chemistry have improved the material characteristics of breast implants and reduced capsular contracture [64]. However, the incidence of capsular contracture after breast implant surgery is up to $30 \%$ and its etiology remains unclear $[65,66]$. The modified Baker classification of capsular contracture includes degree I to IV [67]. Possible explanations for this important complication include chemical interference of the implant in the surrounding tissues, mechanical impact by the anatomical position of the implant, and the effect of bacteria growing in biofilms on the implant surface [68]. Another possible cause of capsular contracture is the presence of bacteria growing as biofilm on the surface, which may cause persistent low-grade inflammation of the surrounding tissue, leading to formation of capsular fibrosis and subsequent contracture $[69,70]$. A significant correlation between the degree of capsular contracture and the presence of biofilm on breast implants was demonstrated by several authors, especially when using a sonication technique $[9,10$, 71]. In a recent study, 112 breast implants were sonicated. Fifty two of them had a positive sonication fluid culture $(46 \%)$. Among positive sonication fluid cultures, $P$. acnes was isolated in most cases (54\%). P. acnes seems to have a role especially in Baker grade IV (Figure 3) [72]. Its origin is most likely the patient skin or colonized mammary ducts at the incision site [62].

3.4. Infections of Intraocular Lenses. Infectious endophthalmitis is the most devastating complication of intraocular surgery. The incidence of infection after cataract surgery and posterior chamber lens implantation is low, reported from 0.07 to $0.33 \%$ [73]. Bacterial biofilm is produced in the intraocular lenses by microorganisms which adhere to the lenses [74]. Postoperative endophthalmitis can be classified into acute and delayed infection. While acute endophthalmitis usually occurs soon after surgery and is caused by S. aureus, Streptococcus spp., or coagulase-negative staphylococci, delayed infections appear from months to years after surgery and are predominantly caused by lowvirulent microorganism such as $P$. acnes, Actinomyces spp. or Corynebacterium spp. [75]. Endophthalmitis diagnosis is based on the appearance of ocular signs and symptoms combined with microscopic and microbiologic examination of the intraocular samples [76]. The most characteristic manifestation of delayed postoperative endophthalmitis is

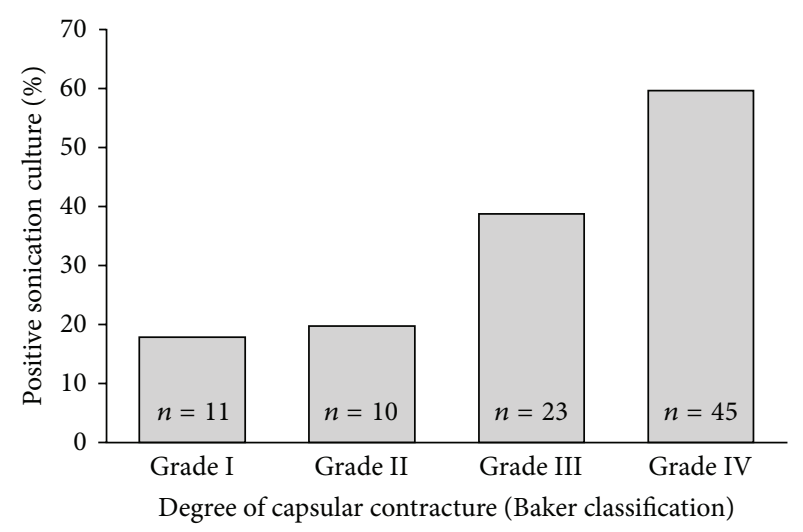

FIGURE 3: High correlation between the degree of capsular contracture and sonication culture of 89 removed breast implants without clinical signs of infection $(P$ for trend $<0.001$ ). Reproduced with permission from Rieger et al. [71].

the appearance of white plaques on the lens capsule or the intraocular lens associated with chronic, recurring intraocular infection [75]. Cultures of vitreous biopsy sample often fail to detect the causative microorganisms due to their low number and low virulence in delayed postoperative endophthalmitis [76]. Molecular diagnostic techniques by PCR have several advantages, although they are not always routinely implemented [75]. The surgical approach, especially in $P$. acnes cases, involves a pars planavitrectomy and may include a selective posterior capsulectomy with intraocular injection of antibiotics or a total capsulectomy with intravitreous antibiotics as well as extraction of the intraocular lens [77].

3.5. Neurosurgical Shunt Infection. P. acnes is increasingly documented in neurosurgical infection involving internal cerebrospinal fluid (CSF) shunts and external ventricular drains (EVD). Internal shunts generally transfer CSF into the peritoneal cavity (ventriculo-peritoneal shunts) but can be placed also into the right atrium (ventriculo-atrial shunts) or rarely in the pleural space, ureter, gall bladder, or fallopian tube [78]. Internal CSF shunt infection constitutes a serious complication with considerable mortality and morbidity, especially in pediatric patients [79]. The infection rate ranges from 1.5 to $38 \%$ [80].

Shunt infections can be classified as early or late depending on whether these infections occur before or after the first year of surgery [79]. Early shunt infections are mainly caused by skin microorganisms introduced during surgery [81]. Late shunt infections are less frequent, $<1 \%$ annually [82], and usually related to peritonitis (generally due to appendicitis) or to hematogenous sources from secondary infections [83]. Clinical manifestations include fever, shunt malfunction, malaise, poor feeding, peritoneal signs, localized abdominal abscess/CSF collection, and wound breakdown [83, 84]. In the absence of fever, differentiation between shunt dysfunction and shunt infection is difficult $[20,85]$. Moreover, allergic reactions to shunt material such as silicone or ethylene oxide may also mimic shunt infections [86, 87]. A young age at the time of initial shunt placement and a short time interval 
from previous surgical revision are risk factors associated with shunt infection [88]. In general, coagulase-negative staphylococci, $S$. aureus, and $P$. acnes are the most common infecting microorganisms implicated in shunt infections [89]. Although $P$. acnes shunt infections are mainly triggered by bacterial contamination from the skin during surgery, symptoms may occur weeks to years after shunt placement or manipulation [20].

Shunt infection is diagnosed based on the combination of clinical signs, CSF cell count and CSF culture sampled through a reservoir tap or lumbar puncture [89]. Differentiation between true infections and contaminations remains difficult. Visualization of microorganisms after Gram straining of CSF is often not possible, and cellular and chemical fluid changes may be subtle [20]. P. acnes shunt infections typically are indolent and present with normal serum CRP levels [90]. Patients present with low initial leukocyte count, percentage of neutrophils, high peak of eosinophil percentage, and minor changes in CSF including glucose or protein levels [20,91]. However, CSF eosinophilia could be associated with reactions to foreign substances, particles or blood, and obstruction of tubing but also by infection caused by coagulase-negative staphylococci [92]. Therefore, culture of CSF remains the most valuable tool for the diagnosis of shunt-associated infection [20].

The most effective treatment for $P$. acnes shunt infection is shunt removal, temporary placement of an external ventricular drainage or ventricular taps (if needed), and treatment with high-dose intravenous penicillin $G[20,93]$. Retention of the distal shunt part often leads to relapse of infection and shunt failure [94]. A new shunt should be placed when CSF becomes sterile [94]. Antibiotic-impregnated shunt systems were introduced to prevent shunt infection [80]. Shunt catheters can be impregnated with antibiotics (often rifampicin or clindamycin). By using these catheters with antibiotics, there is a risk of an increase in the rate of antibiotic resistance rate due to selective pressure. In a recent study, the incidence of CSF shunt infection was lower in patients with antibiotic-impregnated shunt systems compared with those without [95].

External ventricular drains (EVDs) are used in acute hydrocephalus to prevent further brain damage due to high CSF pressure. The rate of external ventricular drainsassociated infection ranges from 5 to $22 \%$ in high-risk patients [96-98]. Factors associated with increased risk of infection are intraventricular or subarachnoid hemorrhage, cranial fracture with CSF leakage, and catheter irrigation [96, 99-102]. Although several studies demonstrated that prolonged external ventricular drains-indwelling time ( $>3$ to 5 days) constitute a risk factor for external ventricular drainsassociated infection $[98,103-106]$, it remains unclear whether a regular external ventricular drains exchange can reduce the infection risk [99, 107-110]. EVD-associated infection may occur up to 10 days after removal of EVD. Clinical signs and symptoms of external ventricular drains-associated infections are nonspecific, such as fever and headache, and often overlap with signs and symptoms of the underlying neurosurgical condition. In addition, CSF parameters may vary widely and none has been shown to be predictive for infection, nor cutoff values have been established [96, 99, 111, 112]. A positive Gram stain or CSF culture are highly specific for external ventricular drains-associated infection but not very sensitive $[113,114]$. Cultures of the external ventricular drains tips may increase the sensitivity, especially when the removed catheter is sonicated. Most authors suggest performing a complete CSF diagnostic workup if EVDassociated infection is suspected, including CSF leukocyte count and differential, as well as CSF Gram stain and culture $[104,115,116]$. In a recent study, although most commonly isolated organisms causing EVD-associated infection were coagulase-negative staphylococci (63\%), P. acnes represented $15 \%$ of the cases [117].

3.6. Spine Implant Infection. The rate of infection after spinal surgery is low, about $0.2 \%$; however, this rate increases up to $12 \%$ when instrumentation is used [118-120]. Nevertheless, the microbiologic diagnosis of spinal implant infection can be challenging. Spinal implant infections can be classified as early or late depending on whether the infection occurs before or after the first month of surgery [121]. Although $P$. acnes and $S$. epidermidis are the most common bacterial causes of late postoperative infection [39], P. acnes is also related to $3-50 \%$ of early postoperative infections $[121,122]$. Clinical manifestations of spine implant infection are usually nonspecific like back pain and paravertebral spasms [123]. Other common symptoms include drainage and localized swelling or fullness along the length of the incision $[119,120]$. Fever is infrequently reported [123]. Inflammatory biomarkers such as CRP, ESR, and WBC values are unreliable as diagnostic markers of low grade spinal implant infections because they may be within the normal range [121]. Presence of infection is usually confirmed by radiographic and microbiological findings. Magnetic resonance imaging (MRI) is considered as the best diagnostic imaging approach (when no device is present) to detect spinal infections [123]. The causative pathogen can be isolated by culturing samples taken by biopsy or peri-implant tissues [124]. Implant sonication is more sensitive than peri-implant tissue culture [39]. The management of spinal implant infection is controversial. While some authors recommend serial debridement surgeries with implant retention $[125,126]$, others advocate implant removal [127]. Contraindications to hardware removal are stated in cases where fusion has not yet taken place [128]. Improved infection-free interval has been reported using long-term oral suppressive antibiotics [125].

\section{Treatment}

The management of severe infections caused by $P$. acnes involves a combination of intravenous antimicrobial agents and surgical procedures (e.g., removal of the device and/or debridement of the surgical site). For serious infections, penicillin $\mathrm{G}$ and ceftriaxone are considered antibiotics of first choice [129], with vancomycin and daptomycin as alternatives in case of $\beta$-lactam allergy or antimicrobial resistance. Clindamycin, tetracycline, and levofloxacin are oral alternatives for nonserious infections, mostly skin diseases [130]. 
Rifampin is considered active against $P$. acnes biofilm [131]. Importantly, $P$. acnes is intrinsically resistant to metronidazole and fosfomycin. Aminoglycosides have generally weak activity and should not be used in the treatment of $P$. acnes infections.

\section{Outlook}

Sonication of explanted prosthetic material has shown to be more sensitive than conventional microbiological culture in the diagnosis of foreign body infections, especially in orthopedic prosthesis, breast implant, and cardiac devices $[10,132,133]$. Formation of $P$. acnes biofilms on implants highlights the importance of vortexing/sonication to detach the microorganism prior to culture $[134,135]$. Therefore, sonication procedure should be applied routinely to all types of implants in order to improve the diagnosis of implantassociated infections caused by $P$. acnes. Also, disruption of the periprosthetic tissue samples improves the diagnosis as adherent cells are detached and removed [136]. Otherwise, new molecular methods for implant-associated infections may be developed in the future to provide rapid and sensitive detection of $P$. acnes. Moreover, these techniques are not affected by previously administered antibiotics. These new techniques would also be able to detect virulence or antibiotic resistance genes and specific mRNA to differentiate active from latent or previous infection. Coating of implants with antimicrobial substances may avoid colonization of the surface by microorganisms and reduce the risk of biofilm formation and clinical infections. Our understanding of the role of $P$. acnes in human diseases will likely continue to increase as new associations and pathogenic mechanisms will be discovered.

\section{References}

[1] E. A. Grice and J. A. Segre, "The skin microbiome," Nature Reviews Microbiology, vol. 9, no. 4, pp. 244-253, 2011.

[2] G. Funke, A. Von Graevenitz, J. E. Clarridge III, and K. A. Bernard, "Clinical microbiology of Coryneform bacteria," Clinical Microbiology Reviews, vol. 10, no. 1, pp. 125-159, 1997.

[3] H. Brüggemann, "Insights in the pathogenic potential of Propionibacterium acnes from its complete genome," Seminars in Cutaneous Medicine and Surgery, vol. 24, no. 2, pp. 67-72, 2005.

[4] R. J. Cohen, B. A. Shannon, J. E. McNeal, T. Shannon, and K. L. Garrett, "Propionibacterium acnes associated with inflammation in radical prostatectomy specimens: a possible link to cancer evolution?" Journal of Urology, vol. 173, no. 6, pp. 19691974, 2005.

[5] M. Colina, A. Lo Monaco, M. Khodeir, and F. Trotta, "Propionibacterium acnes and SAPHO syndrome: a case report and literature review," Clinical and Experimental Rheumatology, vol. 25, no. 3, pp. 457-460, 2007.

[6] T. Yamada, Y. Eishi, S. Ikeda et al., "In situ localization of Propionibacterium acnes DNA in lymph nodes from sarcoidosis patients by signal amplification with catalysed reporter deposition," Journal of Pathology, vol. 198, no. 4, pp. 541-547, 2002.

[7] H. Ichikawa, M. Kataoka, J. Hiramatsu et al., "Quantitative analysis of propionibacterial DNA in bronchoalveolar lavage cells from patients with sarcoidosis," Sarcoidosis Vasculitis and Diffuse Lung Diseases, vol. 25, no. 1, pp. 15-20, 2008.

[8] A. Stirling, T. Worthington, M. Rafiq, P. A. Lambert, and T. S. J. Elliott, "Association between sciatica and Propionibacterium acnes," Lancet, vol. 357, no. 9273, pp. 2024-2025, 2001.

[9] J. L. Del Pozo, N. V. Tran, P. M. Petty et al., "Pilot study of association of bacteria on breast implants with capsular contracture," Journal of Clinical Microbiology, vol. 47, no. 5, pp. 13331337, 2009.

[10] U. M. Rieger, G. Pierer, N. J. Lüscher, and A. Trampuz, "Sonication of removed breast implants for improved detection of subclinical infection," Aesthetic Plastic Surgery, vol. 33, no. 3, pp. 404-408, 2009.

[11] A. Conen, L. N. Walti, A. Merlo, U. Fluckiger, M. Battegay, and A. Trampuz, "Characteristics and treatment outcome of cerebrospinal fluid shunt-associated infections in adults: a retrospective analysis over an 11-year period," Clinical Infectious Diseases, vol. 47, no. 1, pp. 73-82, 2008.

[12] F. Delahaye, S. Fol, M. Célard et al., "Propionibacterium acnes infective endocarditis. Study of 11 cases and review of literature," Archives des Maladies du Coeur et des Vaisseaux, vol. 98, no. 12, pp. 1212-1218, 2005.

[13] V. A. Deramo and T. D. Ting, "Treatment of Propionibacterium acnes endophthalmitis," Current Opinion in Ophthalmology, vol. 12, no. 3, pp. 225-229, 2001.

[14] R. Haidar, M. Najjar, A. D. Boghossian, and Z. Tabbarah, "Propionibacterium acnes causing delayed postoperative spine infection: review," Scandinavian Journal of Infectious Diseases, vol. 42, no. 6-7, pp. 405-411, 2010.

[15] K. E. Piper, M. J. Jacobson, R. H. Cofield et al., "Microbiologic diagnosis of prosthetic shoulder infection by use of implant sonication," Journal of Clinical Microbiology, vol. 47, no. 6, pp. 1878-1884, 2009.

[16] S. Delgado, A. Suárez, and B. Mayo, "Identification, typing and characterisation of Propionibacterium strains from healthy mucosa of the human stomach," International Journal of Food Microbiology, vol. 149, no. 1, pp. 65-72, 2011.

[17] E. M. Gribbon, J. G. Shoesmith, W. J. Cunliffe, and K. T. Holland, "The microaerophily and photosensitivity of Propionibacterium acnes," Journal of Applied Bacteriology, vol. 77, no. 5, pp. 583590, 1994.

[18] J. H. Cove, K. T. Holland, and W. J. Cunliffe, "Effects of oxygen concentration on biomass production, maximum specific growth rate and extracellular enzyme production by three species of cutaneous propionibacteria grown in continuous culture," Journal of General Microbiology, vol. 129, no. 11, pp. 3327-3334, 1983.

[19] Z. Csukás, B. Banizs, and F. Rozgonyi, "Studies on the cytotoxic effects of Propionibacterium acnes strains isolated from cornea," Microbial Pathogenesis, vol. 36, no. 3, pp. 171-174, 2004.

[20] R. Viraraghavan, B. Jantausch, and J. Campos, "Late-onset central nervous system shunt infections with Propionibacterium acnes: diagnosis and management," Clinical Pediatrics, vol. 43, no. 4, pp. 393-397, 2004.

[21] P. Schäfer, B. Fink, D. Sandow, A. Margull, I. Berger, and L. Frommelt, "Prolonged bacterial culture to identify late periprosthetic joint infection: a promising strategy," Clinical Infectious Diseases, vol. 47, no. 11, pp. 1403-1409, 2008.

[22] S. M. Butler-Wu, E. M. Burns, P. S. Pottinger et al., "Optimization of periprosthetic culture for diagnosis of Propionibacterium acnes prosthetic joint infection," Journal of Clinical Microbiology, vol. 49, no. 7, pp. 2490-2495, 2011. 
[23] S. Corvec, M. E. Portillo, B. M. Pasticci, O. Borens, and A. Trampuz, "Epidemiology and new developments in the diagnosis of prosthetic joint infection," The International Journal of Artificial Organs, vol. 35, no. 10, pp. 923-934, 2012.

[24] M. E. Portillo, M. Salvadó, A. Trampuz et al., "Sonication versus vortexing of implants for diagnosis of prosthetic joint infection," Journal of Clinical Microbiology, vol. 51, no. 2, pp. 591-594, 2013.

[25] L. Guío, C. Sarriá, C. de Las Cuevas, C. Gamallo, and J. Duarte, "Chronic prosthetic valve endocarditis due to Propionibacterium acnes: an unexpected cause of prosthetic valve dysfunction," Revista Espanola de Cardiologia, vol. 62, no. 2, pp. 167-177, 2009.

[26] A. Perry and P. Lambert, "Propionibacterium acnes: infection beyond the skin," Expert Review of Anti-Infective Therapy, vol. 9, no. 12, pp. 1149-1156, 2011.

[27] J. L. Johnson and C. S. Cummins, "Cell wall composition and deoxyribonucleic acid similarities among the anaerobic coryneforms, classical propionibacteria, and strains of Arachnia propionica," Journal of Bacteriology, vol. 109, no. 3, pp. 1047-1066, 1972.

[28] A. McDowell, A. L. Perry, P. A. Lambert, and S. Patrick, "A new phylogenetic group of Propionibacterium acnes," Journal of Medical Microbiology, vol. 57, no. 2, pp. 218-224, 2008.

[29] A. McDowell, S. Valanne, G. Ramage et al., "Propionibacterium acnes types I and II represent phylogenetically distinct groups," Journal of Clinical Microbiology, vol. 43, no. 1, pp. 326-334, 2005.

[30] E. Nagy, E. Urban, S. Becker et al., "MALDI-TOF MS fingerprinting facilitates rapid discrimination of phylotypes I, II and III of Propionibacterium acnes," Anaerobe, vol. 20, pp. 20-26, 2013.

[31] S. Valanne, A. McDowell, G. Ramage et al., "CAMP factor homologues in Propionibacterium acnes: a new protein family differentially expressed by types I and II," Microbiology, vol. 151, no. 5, pp. 1369-1379, 2005.

[32] E. Brzuszkiewicz, J. Weiner, A. Wollherr et al., "Comparative genomics and transcriptomics of Propionibacterium acnes," PLoS ONE, vol. 6, no. 6, Article ID e21581, 2011.

[33] J. Hunyadkürti, Z. Feltóti, B. Horváth et al., "Complete genome sequence of Propionibacterium acnes type IB strain 6609," Journal of Bacteriology, vol. 193, no. 17, pp. 4561-4562, 2011.

[34] M. F. Sampedro, K. E. Piper, A. McDowell et al., "Species of Propionibacterium and Propionibacterium acnes phylotypes associated with orthopedic implants," Diagnostic Microbiology and Infectious Disease, vol. 64, no. 2, pp. 138-145, 2009.

[35] J. Cobo and J. L. Del Pozo, "Prosthetic joint infection: diagnosis and management," Expert Review of Anti-Infective Therapy, vol. 9, no. 9, pp. 787-802, 2011.

[36] A. Trampuz, K. E. Piper, M. J. Jacobson et al., "Sonication of removed hip and knee prostheses for diagnosis of infection," The New England Journal of Medicine, vol. 357, no. 7, pp. 654-663, 2007.

[37] W. Zimmerli, A. Trampuz, and P. E. Ochsner, "Current concepts: prosthetic-joint infections," The New England Journal of Medicine, vol. 351, no. 16, pp. 1645-1654, 2004.

[38] J. L. Del Pozo and R. Patel, "Infection associated with prosthetic joints," The New England Journal of Medicine, vol. 361, no. 8, pp. 787-794, 2009.

[39] M. F. Sampedro, P. M. Huddleston, K. E. Piper et al., "A biofilm approach to detect bacteria on removed spinal implants," Spine, vol. 35, no. 12, pp. 1218-1224, 2010.
[40] G. Bori, A. Soriano, S. García et al., "Low sensitivity of histology to predict the presence of microorganisms in suspected aseptic loosening of a joint prosthesis," Modern Pathology, vol. 19, no. 6, pp. 874-877, 2006.

[41] C. C. Dodson, E. V. Craig, F. A. Cordasco et al., "Propionibacterium acnes infection after shoulder arthroplasty: a diagnostic challenge," Journal of Shoulder and Elbow Surgery, vol. 19, no. 2, pp. 303-307, 2010.

[42] K. E. Piper, M. Fernandez-Sampedro, K. E. Steckelberg et al., "Creactive protein, erythrocyte sedimentation rate and orthopedic implant infection," PLoS ONE, vol. 5, no. 2, Article ID e9358, 2010.

[43] A. Trampuz, A. D. Hanssen, D. R. Osmon, J. Mandrekar, J. M. Steckelberg, and R. Patel, "Synovial fluid leukocyte count and differential for the diagnosis of prosthetic knee infection," American Journal of Medicine, vol. 117, no. 8, pp. 556-562, 2004.

[44] A. Trampuz, J. Steinrücken, M. Clauss et al., "New methods for the diagnosis of implant-associated infections," Revue Medicale Suisse, vol. 6, no. 243, pp. 731-734, 2010.

[45] O. Borens, F. Nussbaumer, R. Baalbaki, and A. Trampuz, "Update on implant related infections in orthopaedic surgery. Diagnosis and treatment," Revue Medicale Suisse, vol. 5, no. 230, pp. 2563-2568, 2009.

[46] M. E. Portillo, M. Salvadó, L. Sorli et al., "Multiplex PCR of sonication fluid accurately differentiates between prosthetic joint infection and aseptic failure," Journal of Infection, vol. 65, no. 6, pp. 541-548, 2012.

[47] Y. Achermann, M. Vogt, M. Leimig, J. Wüst, and A. Trampuz, "Improved diagnosis of periprosthetic joint infection by multiplex PCR of sonication fluid from removed implants," Journal of Clinical Microbiology, vol. 48, no. 4, pp. 1208-1214, 2010.

[48] C. L. Nelson, A. C. McLaren, S. G. McLaren, J. W. Johnson, and M. S. Smeltzer, "Is aseptic loosening truly aseptic?" Clinical Orthopaedics and Related Research, no. 437, pp. 25-30, 2005.

[49] J. M. Sierra, S. García, J. C. Martínez-Pastor et al., "Relationship between the degree of osteolysis and cultures obtained by sonication of the prostheses in patients with aseptic loosening of a hip or knee arthroplasty," Archives of Orthopaedic and Trauma Surgery, vol. 131, no. 10, pp. 1357-1361, 2011.

[50] J. Holinka, L. Bauer, A. M. Hirschl, W. Graninger, R. Windhager, and E. Presterl, "Sonication cultures of explanted components as an add-on test to routinely conducted microbiological diagnostics improve pathogen detection," Journal of Orthopaedic Research, vol. 29, no. 4, pp. 617-622, 2011.

[51] M. E. Portillo, M. Salvadó, A. Alier et al., "Prosthesis failure within 2 years of implantation is highly predictive of infection," Clinical Orthopaedics and Related Research, vol. 471, no. 11, pp. 3672-3678, 2013.

[52] W. Y. Vanagt, W. J. Daenen, and T. Delhaas, "Propionibacterium acnes endocarditis on an annuloplasty ring in an adolescent boy," Heart, vol. 90, no. 9, p. e56, 2004.

[53] A. H. Mohsen, A. Price, E. Ridgway, J. N. West, S. Green, and M. W. McKendrick, "Propionibacterium acnes endocarditis in a native valve comlicated by intraventricular abscess: a case report and review," Scandinavian Journal of Infectious Diseases, vol. 33, no. 5, pp. 379-380, 2001.

[54] H. Gunthard, A. Hany, M. Turina, and J. Wust, "Propionibacterium acnes as a cause of aggressive aortic valve endocarditis and importance of tissue grinding: case report and review," Journal of Clinical Microbiology, vol. 32, no. 12, pp. 3043-3045, 1994.

[55] T. Lalani, A. K. Person, S. S. Hedayati et al., "Propionibacterium endocarditis: a case series from the International Collaboration 
on Endocarditis Merged Database and Prospective Cohort Study," Scandinavian Journal of Infectious Diseases, vol. 39, no. 10, pp. 840-848, 2007.

[56] D. T. Durack, A. S. Lukes, and D. K. Bright, "New criteria for diagnosis of infective endocarditis: utilization of specific echocardiographic findings," American Journal of Medicine, vol. 96, no. 3, pp. 200-209, 1994.

[57] S. Durupt, A. Boibieux, M. Ballet-Mechain et al., "Propionibacterium acnes endocarditis: two cases and a review of the literature," Presse Medicale, vol. 27, no. 36, pp. 1839-1841, 1998.

[58] T. T. Huynh, A. D. Walling, M. A. Miller, T. K. Leung, Y. Leclerc, and L. Dragtakis, "Propionibacterium acnes endocarditis," Canadian Journal of Cardiology, vol. 11, no. 9, pp. 785-787, 1995.

[59] R. R. Cook and L. L. Perkins, "The prevalence of breast implants among women in the United States," Current Topics in Microbiology and Immunology, vol. 210, pp. 418-425, 1996.

[60] R. C. Herdman and T. J. Fahey, "Silicone breast implants and cancer," Cancer Investigation, vol. 19, no. 8, pp. 821-832, 2001.

[61] L. L. Washer and K. Gutowski, "Breast implant infections," Infectious disease clinics of North America, vol. 26, no. 1, pp. 111-125, 2012.

[62] B. Pittet, D. Montandon, and D. Pittet, "Infection in breast implants," Lancet Infectious Diseases, vol. 5, no. 2, pp. 94-106, 2005.

[63] R. O. Darouiche, "Treatment of infections associated with surgical implants," The New England Journal of Medicine, vol. 350, no. 14, pp. 1422-1429, 2004.

[64] V. L. Young and M. E. Watson, "Breast implant research: where we have been, where we are, where we need to go," Clinics in Plastic Surgery, vol. 28, no. 3, pp. 451-483, 2001.

[65] R. A. Ersek, "Rate and incidence of capsular contracture: a comparison of smooth and textured silicone double-lumen breast prostheses," Plastic and Reconstructive Surgery, vol. 87, no. 5, pp. 879-884, 1991.

[66] S. E. Gabriel, J. E. Woods, W. M. O’Fallon, C. M. Beard, L. T. Kurland, and L. J. Melton III, "Complications leading to surgery after breast implantation," The New England Journal of Medicine, vol. 336, no. 10, pp. 677-682, 1997.

[67] S. L. Spear, J. L. Baker Jr., and H. H. Caffee, "Classification of capsular contracture after prosthetic breast reconstruction," Plastic and Reconstructive Surgery, vol. 96, no. 5, pp. 1119-1124, 1995.

[68] M. Embrey, E. E. Adams, B. Cunningham, W. Peters, V. L. Young, and G. L. Carlo, "A review of the literature on the etiology of capsular contracture and a pilot study to determine the outcome of capsular contracture interventions," Aesthetic Plastic Surgery, vol. 23, no. 3, pp. 197-206, 1999.

[69] D. T. Netscher and A. K. Deva, "Subclinical infection as a possible cause of significant breast capsules," Plastic and Reconstructive Surgery, vol. 113, no. 7, pp. 2229-2230, 2004.

[70] A. Pajkos, A. K. Deva, K. Vickery, C. Cope, L. Chang, and Y. E. Cossart, "Detection of subclinical infection in significant breast implant capsules," Plastic and Reconstructive Surgery, vol. 111, no. 5, pp. 1605-1611, 2003.

[71] U. M. Rieger, J. Mesina, D. F. Kalbermatten et al., "Bacterial biofilms and capsular contracture in patients with breast implants," British Journal of Surgery, vol. 100, pp. 768-774, 2013.

[72] C. Y. Ahn, C. Y. Ko, E. A. Wagar, R. S. Wong, and W. W. Shaw, "Microbial evaluation: 139 Implants removed from symptomatic patients," Plastic and Reconstructive Surgery, vol. 98 , no. 7, pp. 1225-1229, 1996.
[73] M. S. Kresloff, A. A. Castellarin, and M. A. Zarbin, "Endophthalmitis," Survey of Ophthalmology, vol. 43, no. 3, pp. 193-224, 1998.

[74] R. P. Casaroli-Marano and A. Adán, "Eye infections associated with ocular implants," Enfermedades Infecciosas y Microbiologia Clinica, vol. 26, no. 9, pp. 581-588, 2008.

[75] C. P. Lohmann, H.-J. Linde, and U. Reischl, "Improved detection of microorganisms by polymerase chain reaction in delayed endophthalmitis after cataract surgery," Ophthalmology, vol. 107, no. 6, pp. 1047-1052, 2000, discussion 1051-1042.

[76] A. Adán, R. P. Casaroli-Marano, O. Gris et al., "Pathological findings in the lens capsules and intraocular lens in chronic pseudophakic endophthalmitis: an electron microscopy study," Eye, vol. 22, no. 1, pp. 113-119, 2008.

[77] M. K. Rahman and E. R. Holz, "Alcaligenes xylosoxidans and Propionibacterium acnes postoperative endophthalmitis in a pseudophakic eye," American Journal of Ophthalmology, vol. 129, no. 6, pp. 813-815, 2000.

[78] Association H, October 2013, http://www.hydroassoc.org/.

[79] C. Baird, D. O'Connor, and T. Pittman, "Late shunt infections," Pediatric Neurosurgery, vol. 31, no. 5, pp. 269-273, 1999.

[80] B. Ratilal, J. Costa, and C. Sampaio, "Antibiotic prophylaxis for surgical introduction of intracranial ventricular shunts: a systematic review," Journal of Neurosurgery: Pediatrics, vol. 1, no. 1, pp. 48-56, 2008.

[81] D. J. Isaacman, M. P. Poirier, M. Hegenbarth, K. A. Lillis, and R. Scarfone, "Ventriculoperitoneal shunt management," Pediatric Emergency Care, vol. 19, no. 2, pp. 119-125, 2003.

[82] S. J. Schiff and W. J. Oakes, "Delayed cerebrospinal-fluid shunt infection in children," Pediatric Neuroscience, vol. 15, no. 3, pp. 131-135, 1989.

[83] M. Vinchon, M.-P. Lemaitre, L. Vallée, and P. Dhellemmes, "Late shunt infection: incidence, pathogenesis, and therapeutic implications," Neuropediatrics, vol. 33, no. 4, pp. 169-173, 2002.

[84] D. Renier, J. Lacombe, and A. Pierre-Kahn, "Factors causing acute shunt infection. Computer analysis of 1174 operations," Journal of Neurosurgery, vol. 61, no. 6, pp. 1072-1078, 1984.

[85] N. P. Barnes, S. J. Jones, R. D. Hayward, W. J. Harkness, and D. Thompson, "Ventriculoperitoneal shunt block: what are the best predictive clinical indicators?" Archives of Disease in Childhood, vol. 87, no. 3, pp. 198-201, 2002.

[86] D. J. Gower, J. C. Lewis, and D. L. Kelly Jr., "Sterile shunt malfunction. A scanning electron microscopic perspective," Journal of Neurosurgery, vol. 61, no. 6, pp. 1079-1084, 1984.

[87] T. Pittman, D. Wiliams, M. Rathore, A. P. Knutsen, and K. R. Mueller, "The role of ethylene oxide allergy in sterile shunt malfunctions," British Journal of Neurosurgery, vol. 8, no. 1, pp. 41-45, 1994.

[88] S. Tuli, J. Drake, J. Lawless, M. Wigg, and M. Lamberti-Pasculli, "Risk factors for repeated cerebrospinal shunt failures in pediatric patients with hydrocephalus," Journal of Neurosurgery, vol. 92, no. 1, pp. 31-38, 2000.

[89] D. H. Fulkerson and J. C. Boaz, "Cerebrospinal fluid eosinophilia in children with ventricular shunts," Journal of Neurosurgery: Pediatrics, vol. 1, no. 4, pp. 288-295, 2008.

[90] H. Westergren, V. Westergren, and U. Forsum, "Propionebacterium acnes in cultures from ventriculo-peritoneal shunts: infection or contamination?" Acta Neurochirurgica, vol. 139, no. 1, pp. 33-36, 1997.

[91] D. H. Fulkerson, S. Vachhrajani, B. N. Bohnstedt et al., "Analysis of the risk of shunt failure or infection related to cerebrospinal fluid cell count, protein level, and glucose levels 
in low-birth-weight premature infants with posthemorrhagic hydrocephalus," Journal of Neurosurgery: Pediatrics, vol. 7, no. 2, pp. 147-151, 2011.

[92] S. Bezerra, T. M. Frigeri, C. M. Severo, J. C. B. Santana, and C. Graeff-Teixeira, "Cerebrospinal fluid eosinophilia associated with intraventricular shunts," Clinical Neurology and Neurosurgery, vol. 113, no. 5, pp. 345-349, 2011.

[93] R. T. Schreffler, A. J. Schreffler, and R. R. Wittler, "Treatment of cerebrospinal fluid shunt infections: a decision analysis," Pediatric Infectious Disease Journal, vol. 21, no. 7, pp. 632-636, 2002.

[94] M. J. McGirt, J. C. Wellons III, S. M. Nimjee, K. R. Bulsara, H. E. Fuchs, and T. M. George, "Comparison of total versus partial revision of initial ventriculoperitoneal shunt failures," Pediatric Neurosurgery, vol. 38, no. 1, pp. 34-40, 2003.

[95] S. L. Parker, W. N. Anderson, S. Lilienfeld, J. T. Megerian, and M. J. Mcgirt, "Cerebrospinal shunt infection in patients receiving antibiotic-impregnated versus standard shunts: a review," Journal of Neurosurgery: Pediatrics, vol. 8, no. 3, pp. 259-265, 2011.

[96] A. P. Lozier, R. R. Sciacca, M. F. Romagnoli et al., "Ventriculostomy-related infections: a critical review of the literature," Neurosurgery, vol. 51, no. 1, pp. 170-182, 2002.

[97] Y. Arabi, Z. A. Memish, H. H. Balkhy et al., "Ventriculostomyassociated infections: incidence and risk factors," American Journal of Infection Control, vol. 33, no. 3, pp. 137-143, 2005.

[98] R. P. Schade, J. Schinkel, L. G. Visser, M. C. Van Dijk, J. H. C. Voormolen, and E. J. Kuijper, "Bacterial meningitis caused by the use of ventricular or lumbar cerebrospinal fluid catheters," Journal of Neurosurgery, vol. 102, no. 2, pp. 229-234, 2005.

[99] C. G. Mayhall, N. H. Archer, and V. A. Lamb, "Ventriculostomyrelated infections. A positive epidemiologic study," The New England Journal of Medicine, vol. 310, no. 9, pp. 553-559, 1984.

[100] K. E. Lyke, O. O. Obasanjo, M. A. Williams, M. O’Brien, R. Chotani, and T. M. Perl, "Ventriculitis complicating use of intraventricular catheters in adult neurosurgical patients," Clinical Infectious Diseases, vol. 33, no. 12, pp. 2028-2033, 2001.

[101] P. J. Aucoin, H. Rosen Kotilainen, and N. M. Gantz, "Intracranial pressure monitors. Epidemiologic study of risk factors and infections," American Journal of Medicine, vol. 80, no. 3, pp. 369376, 1986.

[102] D. Hoefnagel, R. Dammers, M. P. Ter Laak-Poort, and C. J. J. Avezaat, "Risk factors for infections related to external ventricular drainage," Acta Neurochirurgica, vol. 150, no. 3, pp. 209-214, 2008.

[103] G. K. C. Wong, W. S. Poon, S. Wai, L. M. Yu, D. Lyon, and J. M. K. Lam, "Failure of regular external ventricular drain exchange to reduce cerebrospinal fluid infection: result of a randomised controlled trial," Journal of Neurology Neurosurgery and Psychiatry, vol. 73, no. 6, pp. 759-761, 2002.

[104] W. Pfisterer, M. Mühlbauer, T. Czech, and A. Reinprecht, "Early diagnosis of external ventricular drainage infection: results of a prospective study," Journal of Neurology Neurosurgery and Psychiatry, vol. 74, no. 7, pp. 929-932, 2003.

[105] C. H. Lo, D. Spelman, M. Bailey, D. J. Cooper, J. V. Rosenfeld, and J. E. Brecknell, "External ventricular drain infections are independent of drain duration: an argument against elective revision," Journal of Neurosurgery, vol. 106, no. 3, pp. 378-383, 2007.

[106] G. K. C. Wong and W. W. S. Poon, "External ventricular drain infection," Journal of Neurosurgery, vol. 107, no. 1, pp. 248-249, 2007.
[107] M. A. Leverstein-Van Hall, T. E. M. Hopmans, J. W. B. van der Sprenkel et al., "A bundle approach to reduce the incidence of external ventricular and lumbar drain-related infections: clinical article," Journal of Neurosurgery, vol. 112, no. 2, pp. 345353, 2010.

[108] R. Beer, P. Lackner, B. Pfausler, and E. Schmutzhard, "Nosocomial ventriculitis and meningitis in neurocritical care patients," Journal of Neurology, vol. 255, no. 11, pp. 1617-1624, 2008.

[109] D. Dasic, S. J. Hanna, S. Bojanic, and R. S. C. Kerr, "External ventricular drain infection: the effect of a strict protocol on infection rates and a review of the literature," British Journal of Neurosurgery, vol. 20, no. 5, pp. 296-300, 2006.

[110] A. M. Sonabend, Y. Korenfeld, C. Crisman, N. Badjatia, S. A. Mayer, and E. S. Connolly, "Prevention of ventriculostomyrelated infections with prophylactic antibiotics and antibioticcoated external ventricular drains: a systematic review," Neurosurgery, vol. 68, no. 4, pp. 996-1005, 2011.

[111] G. Sundbarg, C.-H. Nordstrom, and S. Soderstrom, "Complications due to prolonged ventricular fluid pressure recording," British Journal of Neurosurgery, vol. 2, no. 4, pp. 485-495, 1988.

[112] S. Muttaiyah, S. Ritchie, A. Upton, and S. Roberts, "Clinical parameters do not predict infection in patients with external ventricular drains: a retrospective observational study of daily cerebrospinal fluid analysis," Journal of Medical Microbiology, vol. 57, no. 2, pp. 207-209, 2008.

[113] G. K. Wong, W. S. Poon, and M. Ip, "Use of ventricular cerebrospinal fluid lactate measurement to diagnose cerebrospinal fluid infection in patients with intraventricular haemorrhage," Journal of Clinical Neuroscience, vol. 15, no. 6, pp. 654-655, 2008.

[114] B. Pfausler, R. Beer, K. Engelhardt et al., "Cell index-a new parameter for the early diagnosis of ventriculostomy (external ventricular drainage)-related ventriculitis in patients with intraventricular hemorrhage?" Acta Neurochirurgica, vol. 146, no. 5, pp. 477-481, 2004.

[115] R. P. Schade, J. Schinkel, F. W. C. Roelandse et al., "Lack of value of routine analysis of cerebrospinal fluid for prediction and diagnosis of external drainage-related bacterial meningitis," Journal of Neurosurgery, vol. 104, no. 1, pp. 101-108, 2006.

[116] W. J. Hader and P. Steinbok, "The value of routine cultures of the cerebrospinal fluid in patients with external ventricular drains," Neurosurgery, vol. 46, no. 5, pp. 1149-1155, 2000.

[117] L. N. Walti, A. Conen, J. Coward, G. F. Jost, and A. Trampuz, "Characteristics of infections associated with external ventricular drains of cerebrospinal fluid," Journal of Infection, vol. 66, pp. 424-431, 2013.

[118] P. Bémer, S. Corvec, S. Tariel et al., "Significance of Propionibacterium acnes-positive samples in spinal instrumentation," Spine, vol. 33, no. 26, pp. E971-976, 2008.

[119] S. B. Chaudhary, M. J. Vives, S. K. Basra, and M. F. Reiter, "Postoperative spinal wound infections and postprocedural diskitis," Journal of Spinal Cord Medicine, vol. 30, no. 5, pp. 441-451, 2007.

[120] B. Bose, "Delayed infection after instrumented spine surgery: case reports and review of the literature," Spine Journal, vol. 3, no. 5, pp. 394-399, 2003.

[121] I. Collins, J. Wilson-MacDonald, G. Chami et al., "The diagnosis and management of infection following instrumented spinal fusion," European Spine Journal, vol. 17, no. 3, pp. 445-450, 2008.

[122] T. J. Kowalski, E. F. Berbari, P. M. Huddleston, J. M. Steckelberg, J. N. Mandrekar, and D. R. Osmon, "The management and outcome of spinal implant infections: contemporary retrospective cohort study," Clinical Infectious Diseases, vol. 44, no. 7, pp. 913920, 2007. 
[123] I. S. Kourbeti, S. Tsiodras, and D. T. Boumpas, "Spinal infections: evolving concepts," Current Opinion in Rheumatology, vol. 20, no. 4, pp. 471-479, 2008.

[124] D. L. Balériaux and C. Neugroschl, "Spinal and spinal cord infection," European Radiology, Supplement, vol. 14, no. 3, pp. E72-E83, 2004.

[125] A. D. O. Levi, C. A. Dickman, and V. K. H. Sonntag, "Management of postoperative infections after spinal instrumentation," Journal of Neurosurgery, vol. 86, no. 6, pp. 975-980, 1997.

[126] M. A. Weinstein, J. P. McCabe, and F. P. Cammisa Jr., "Postoperative spinal wound infection: a review of 2,391 consecutive index procedures," Journal of Spinal Disorders, vol. 13, no. 5, pp. 422426, 2000.

[127] S. Richards, "Delayed infections following posterior spinal instrumentation for the treatment of idiopathic scoliosis," Journal of Bone and Joint Surgery. American, vol. 77, no. 4, pp. 524-529, 1995.

[128] L. Crémet, S. Corvec, P. Bémer et al., "Orthopaedic-implant infections by Escherichia coli: molecular and phenotypic analysis of the causative strains," Journal of Infection, vol. 64, no. 2, pp. 169-175, 2012.

[129] D. R. Osmon, E. F. Berbari, A. R. Berendt et al., "Diagnosis and management of prosthetic joint infection: clinical practice guidelines by the Infectious Diseases Society of America," Clinical Infectious Diseases, vol. 56, pp. el-e25, 2013.

[130] C. Oprica, C. E. Nord, S. Kalenic et al., "European surveillance study on the antibiotic susceptibility of Propionibacterium acnes," Clinical Microbiology and Infection, vol. 11, no. 3, pp. 204213, 2005.

[131] U. F. Tafin, S. Corvec, B. Betrisey, W. Zimmerli, and A. Trampuz, "Role of rifampin against Propionibacterium acnes biofilm in vitro and in an experimental foreign-body infection model," Antimicrobial Agents and Chemotherapy, vol. 56, no. 4, pp. 18851891, 2012.

[132] M. Rohacek, M. Weisser, R. Kobza et al., "Bacterial colonization and infection of electrophysiological cardiac devices detected with sonication and swab culture," Circulation, vol. 121, no. 15, pp. 1691-1697, 2010.

[133] A. Trampuz, K. E. Piper, A. D. Hanssen et al., "Sonication of explanted prosthetic components in bags for diagnosis of prosthetic joint infection is associated with risk of contamination," Journal of Clinical Microbiology, vol. 44, no. 2, pp. 628-631, 2006.

[134] G. Ramage, M. M. Tunney, S. Patrick, S. P. Gorman, and J. R. Nixon, "Formation of Propionibacterium acnes biofilms on orthopaedic biomaterials and their susceptibility to antimicrobials," Biomaterials, vol. 24, no. 19, pp. 3221-3227, 2003.

[135] R. Bayston, W. Ashraf, R. Barker-Davies et al., "Biofilm formation by Propionibacterium acnes on biomaterials in vitro and in vivo: impact on diagnosis and treatment," Journal of Biomedical Materials Research Part A, vol. 81, no. 3, pp. 705-709, 2007.

[136] A.-L. Roux, V. Sivadon-Tardy, T. Bauer et al., "Diagnosis of prosthetic joint infection by beadmill processing of a periprosthetic specimen," Clinical Microbiology and Infection, vol. 17, no. 3, pp. 447-450, 2011. 

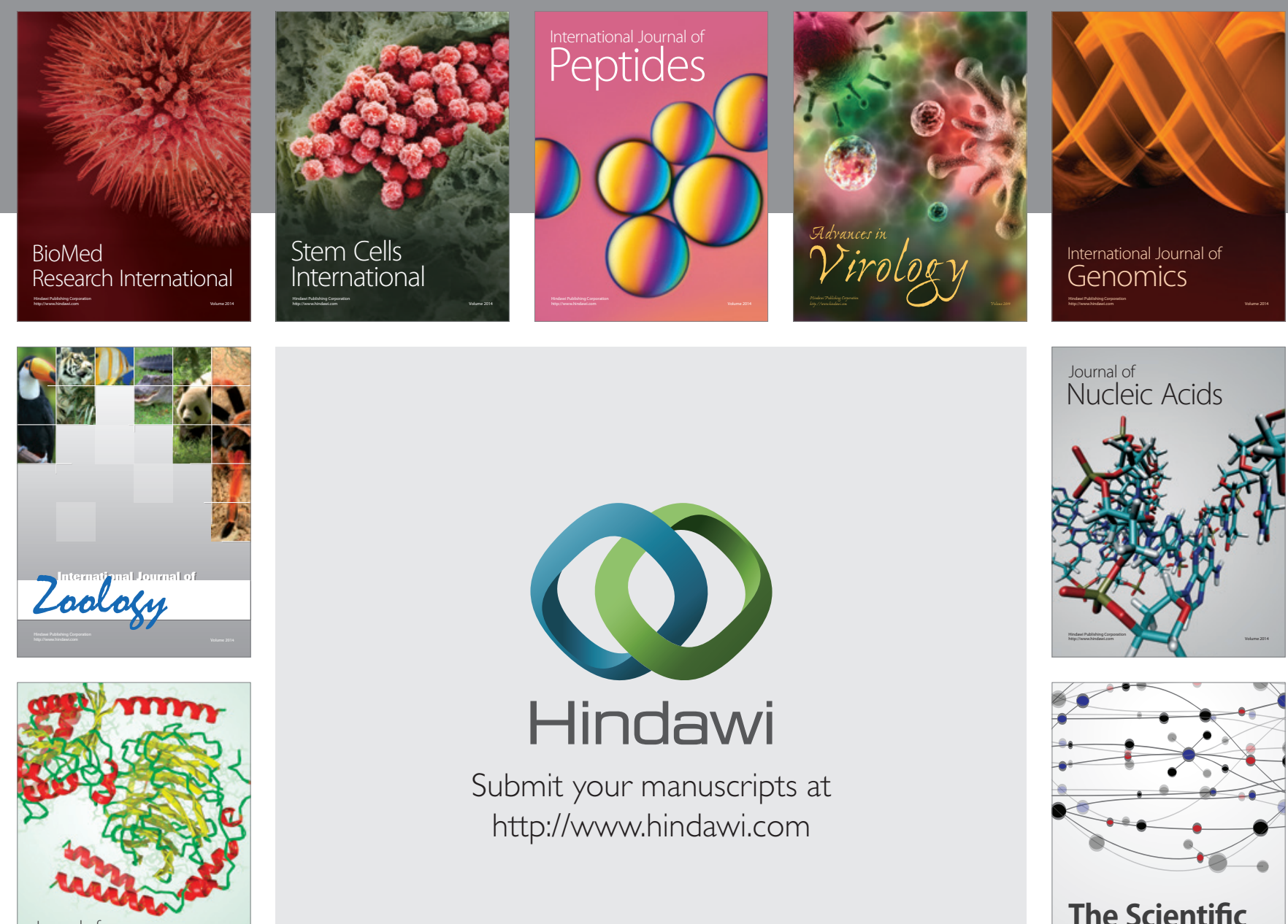

Submit your manuscripts at

http://www.hindawi.com

Journal of
Signal Transduction
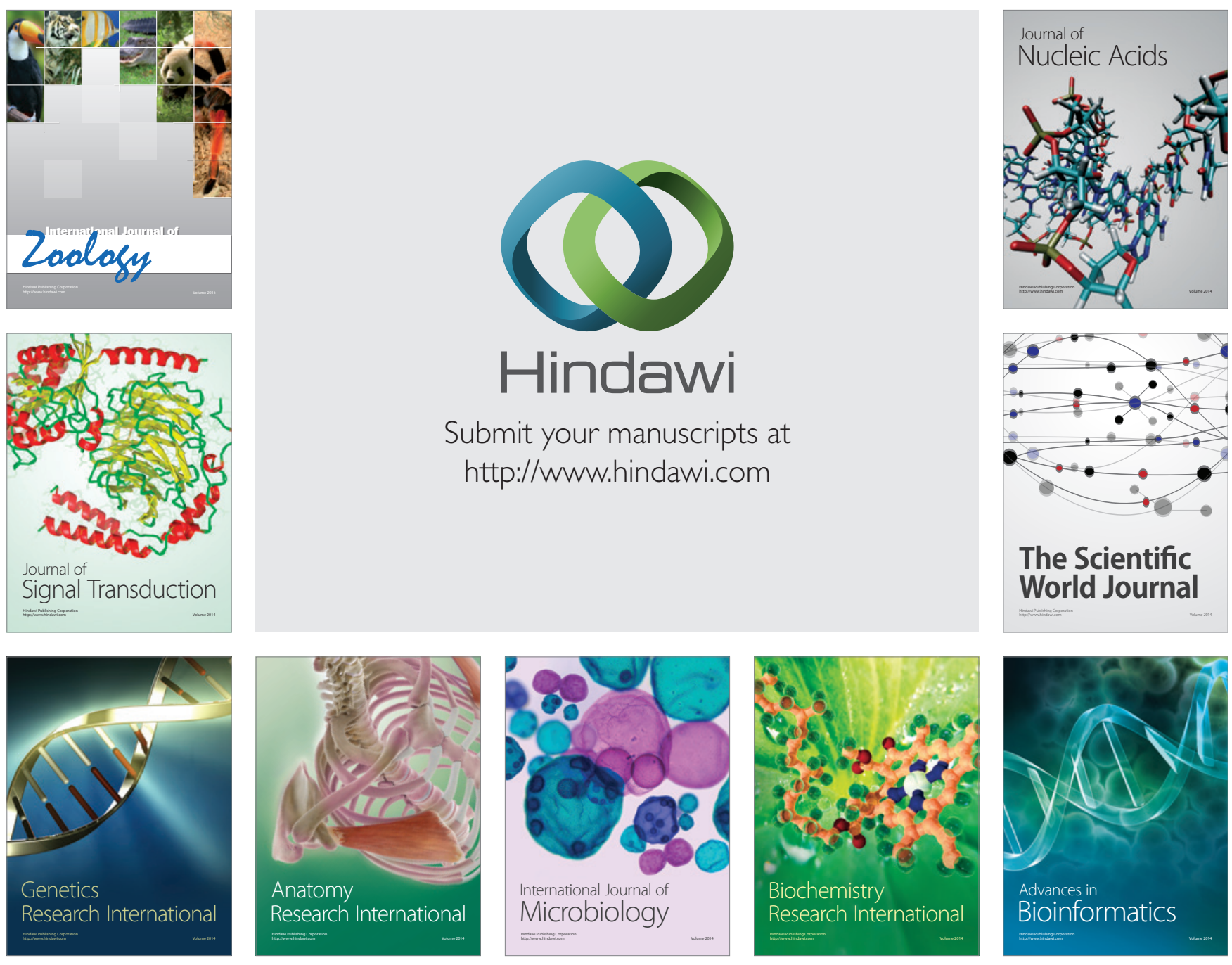

The Scientific World Journal
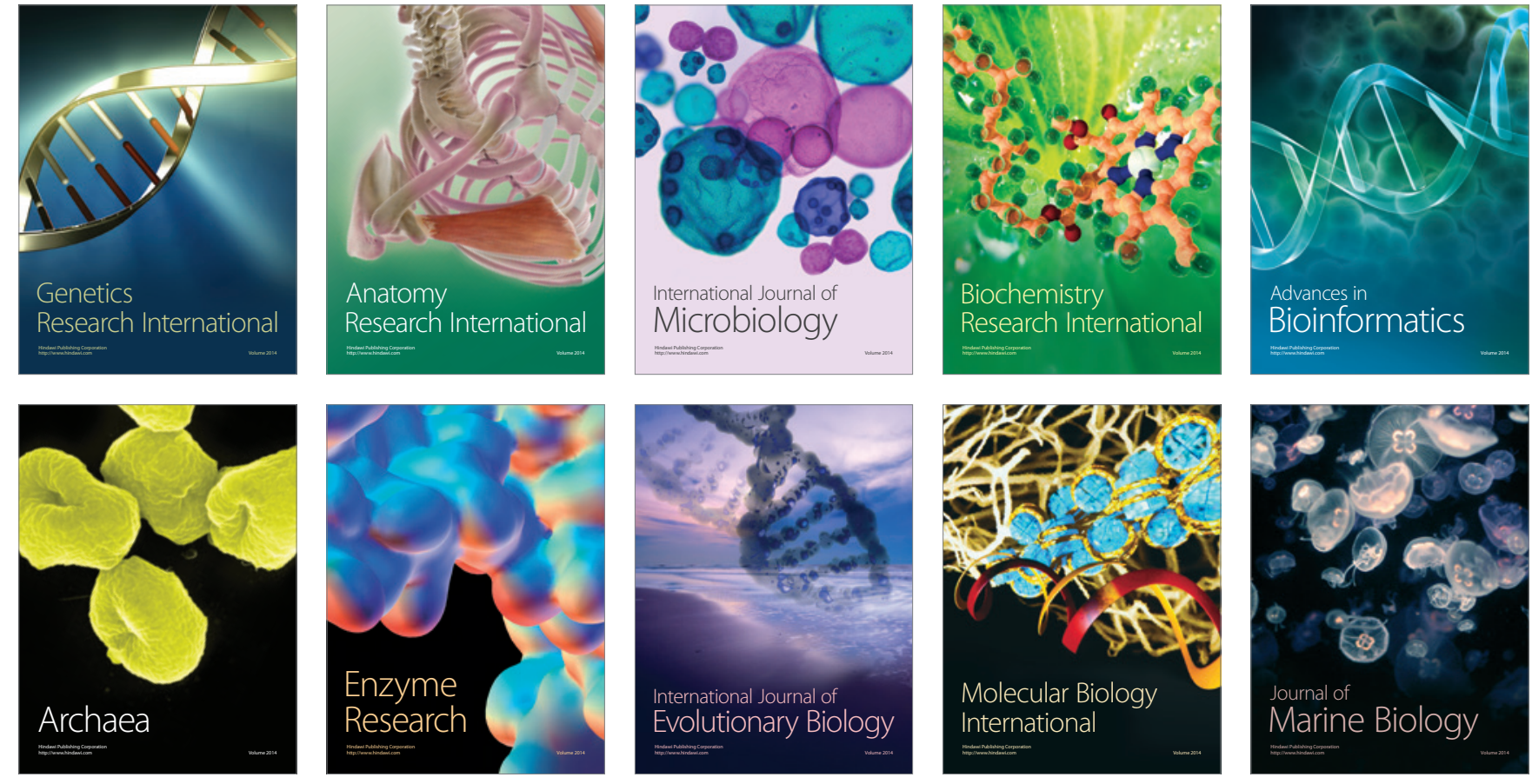